\title{
Effects of tiotropium on lung hyperinflation, dyspnoea and exercise tolerance in COPD
}

\author{
D.E. O'Donnell*, T. Flüge", F. Gerken", A. Hamilton" ${ }^{\#}$, K. Webb*, B. Aguilaniu^, B. Make ${ }^{+}$, \\ H. Magnussen ${ }^{\S}$
}

Effects of tiotropium on lung hyperinflation, dyspnoea and exercise tolerance in COPD. D.E. O'Donnell, T. Flüge, F. Gerken, A. Hamilton, K. Webb, B. Aguilaniu, B. Make, H. Magnussen. (C) ERS Journals Ltd 2004.

ABSTRACT: The aim of this study was to test the hypothesis that use of tiotropium, a new long-acting anticholinergic bronchodilator, would be associated with sustained reduction in lung hyperinflation and, thereby, would improve exertional dyspnoea and exercise performance in patients with chronic obstructive pulmonary disease.

A randomised, double-blind, placebo-controlled, parallel-group study was conducted in 187 patients (forced expiratory volume in one second $44 \pm 13 \%$ pred): 96 patients received $18 \mu \mathrm{g}$ tiotropium and 91 patients received placebo once daily for 42 days. Spirometry, plethysmographic lung volumes, cycle exercise endurance and exertional dyspnoea intensity at $75 \%$ of each patient's maximal work capacity were compared.

On day 42, the use of tiotropium was associated with the following effects at pre-dose and post-dose measurements as compared to placebo: vital capacity and inspiratory capacity (IC) increased, with inverse decreases in residual volume and functional residual capacity. Tiotropium increased post-dose exercise endurance time by $105 \pm 40 \mathrm{~s}$ $(21 \%)$ as compared to placebo on day 42 . At a standardised time near end-exercise (isotime), IC, tidal volume and minute ventilation all increased, whilst dyspnoea decreased by $0.9 \pm 0.3$ Borg scale units.

In conclusion, the use of tiotropium was associated with sustained reductions of lung hyperinflation at rest and during exercise. Resultant increases in inspiratory capacity permitted greater expansion of tidal volume and contributed to improvements in both exertional dyspnoea and exercise endurance.

Eur Respir J 2004; 23: 832-840.

\begin{abstract}
*Respiratory Investigation Unit, Dept of Medicine, Queen's University, Kingston, Ontario, Canada. "Boehringer Ingelheim Pharma $\mathrm{GmbH} \& \mathrm{Co}$. KG, Ingelheim, Germany. UCP-X, Clinique de mail, Grenoble, France. ${ }^{+}$National Jewish Medical and Research Center, Denver, CO, USA. ${ }^{\S}$ Krankenhaus Grosshansdorf, Grosshansdorf, Germany.
\end{abstract}

Correspondence: D.E. O'Donnell, 102 Stuart Street, Kingston, Ontario, Canada K7L 2V6. Fax: 16135491459

E-mail: odonnell@post.queensu.ca

Keywords: Chronic obstructive pulmonary disease, chronic obstructive pulmonary disease treatment, dyspnoea, exercise tolerance, lung hyperinflation, tiotropium

Received: October 162003

Accepted after revision: February 92004

This study was supported by Boehringer Ingelheim Pharma $\mathrm{GmbH}$ \& Co. KG, Ingelheim, Germany. D.E. O'Donnell holds a career scientist award from the Ontario Ministry of Health.
Traditionally, clinical trials that have evaluated the effects of bronchodilators on exercise performance have utilised field tests, such as the 6- and 12-min walk distance, or laboratory tests, such as incremental cycle ergometry [1]. However, the effects of different bronchodilating agents on walking distance and peak symptom-limited oxygen consumption (peak $V^{\prime} \mathrm{O}_{2}$ ) have been quite variable [1-4]. Recently, the current authors have used constant-load cycle endurance testing, at a fixed fraction of the patient's pre-determined peak work rate $(W \max )$ to evaluate bronchodilator efficacy [5, 6]. This approach appears to be more responsive than other tests, as it allows for placebo-controlled comparisons of symptoms and physiological parameters, including exercise endurance time (ET), at a standardised work rate or power output $[5,7]$. Cycle exercise endurance testing, combined with measurements of exertional dyspnoea, ventilation and dynamic operating lung volumes, has been shown to be reliable (reproducible and responsive) [5, 6].

The measurement of operating lung volumes (i.e. endexpiratory (EELV) and end-inspiratory lung volumes) during exercise is relevant to the understanding of the impairmentdisability interface in chronic obstructive pulmonary disease (COPD) [8]. During the increased ventilation of exercise in flow-limited patients, EELV acutely increases above an already high resting value. Studies have shown that this dynamic lung hyperinflation influences inspiratory muscle function, breathing pattern responses, the efficiency of carbon dioxide elimination and the intensity of exertional dyspnoea [8-10].

Tiotropium is a specific muscarinic receptor antagonist with kinetically controlled selectivity for the $\mathbf{M}_{3}$-subtype, which has been shown to achieve sustained bronchodilatation, and to improve health-related quality of life in patients with COPD [11-13]. The improvement in health status is likely to be multifactorial, but enhanced symptom control and increased exercise capability are potentially important factors. Therefore, this study was designed to evaluate the effects of tiotropium on exercise endurance and exertional dyspnoea, and to examine possible mechanisms for this overall functional improvement.

According to the current authors' hypothesis, use of oncedaily tiotropium would be associated with improved tidal expiratory flow rates (and lung emptying), reduced resting and exercise lung hyperinflation, and consequent alleviation of exertional dyspnoea. Sustained volume reduction following tiotropium would allow greater tidal volume $(V \mathrm{~T})$ expansion during exercise and delay the mechanical limitation to ventilation. These factors together would improve exercise performance in COPD. To test this hypothesis, the first large, multicentre, randomised, placebo-controlled, parallelgroup study was performed using detailed exercise testing, to evaluate bronchodilator efficacy over an extended period of 6 weeks. 
Methods

\section{Study subjects}

Subjects included clinically stable patients with COPD aged $40-70$ years with a cigarette smoking history of $\geqslant 10$ pack-yrs, forced expiratory volume in one second (FEV1) $\leqslant 65 \%$ predicted and plethysmographic functional residual capacity $($ FRC) $\geqslant 120 \%$ pred. Patients were excluded in the presence of: 1) significant diseases other than COPD that could contribute to dyspnoea and exercise limitation; 2) a history of asthma, allergic rhinitis or atopy; 3) important contraindications to clinical exercise testing [14]; 4) exercise limitation not related to fatigue or exertional dyspnoea; or 5) participation in a rehabilitation programme for COPD within 6 weeks prior to the screening visit.

Concomitant respiratory medication was permitted if stabilised for at least 6 weeks, prior to, and throughout the duration of the study. Permitted medication included regularly taken oral and inhaled corticosteroids, oral theophylline preparations, and mucolytic agents not containing bronchodilators. Oral and long-acting $\beta_{2}$-agonists were not allowed for at least 1 week, prior to, and throughout the duration of the study. Anticholinergics were withdrawn at least 1 day prior to the screening visit and were not permitted throughout the study. Open-label salbutamol (metered-dose inhaler: $100 \mu \mathrm{g} \cdot$ actuation $^{-1}$ ) was provided as rescue medication during the run-in and treatment periods, but was withheld for $\geqslant 6 \mathrm{~h}$ prior to each visit.

\section{Study design}

This multicentre, randomised, double-blind, placebocontrolled, parallel-group study was first approved by the Medical Ethics Committees of all 12 participating sites. Subjects gave written informed consent before any study procedure. During an initial screening visit (day -15), patients were assessed for their eligibility to participate in the study. At this visit, patients performed pulmonary function tests (body plethysmography, spirometry, single-breath diffusing capacity $(D \mathrm{~L}, \mathrm{CO}))$, followed by a symptom-limited incremental cycle exercise test to determine $W \max$ [9]. Eligible patients completed another two visits (days -10 and -5) during a "runin" phase to familiarise themselves with all testing procedures and to establish a standardised training history. On these days, pulmonary function tests were followed by a constantload exercise test at $75 \% W \max$. On day 0 , patients were randomised to a 42-day treatment period with either $18 \mu \mathrm{g}$ tiotropium (Spiriva $\mathbb{R}$; Boehringer Ingelheim, Ingelheim, Germany) or placebo via a dry powder inhaler device

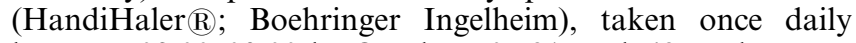
between 08:00-09:00 $\mathrm{h}$. On days 0,21 and 42, pulmonary function tests were performed before ("trough") and $80 \mathrm{~min}$ after dosing, followed by a constant-load exercise test starting $135 \mathrm{~min}$ after dosing. All visits were conducted at a similar time in the morning. Prior to first administration of study medication (day 0), the baseline dyspnoea index (BDI) was used to assess chronic activity-related dyspnoea [15]. Change in dyspnoea over time was evaluated by the transition dyspnoea index (TDI) prior to dosing on days 21 and 42 [15]. Patients completed a daily diary card indicating each dose of study drug and rescue medication taken.

Quality control for the study was ensured by: performance of practice runs for pulmonary function and exercise testing at site initiation visits; source data verification performed at each centre by on-site study monitors; audits performed by the sponsor's clinical quality assurance at two centres with high subject recruitment; and careful review of data quality prior to unblinding.

\section{Pulmonary function testing}

Pulmonary function tests were conducted in accordance with recognised standards [16-19]. Evaluation of pulmonary function parameters was performed using the following definitions: "trough" values were measured pre-dose on days 21 and 42, i.e. $\sim 23-24 \mathrm{~h}$ after the preceding dose of trial medication; "trough responses" were the differences between pre-dose values on days 21 and 42 and the pre-dose value on day 0 (pretreatment baseline); "peak responses" reflect the differences between post-dose values on days 0,21 or 42 , and those measured on day -5 , i.e. pretreatment exercise baseline. Measurements of spirometry, lung volumes and $D \mathrm{~L}, \mathrm{CO}$ were expressed as per cent predicted normal values [17, 18]. Predicted normal values for inspiratory capacity (IC) were calculated as predicted total lung capacity (TLC) minus predicted FRC.

\section{Exercise testing}

Symptom-limited incremental and constant-load exercise testing has been previously described in detail $[6,9,20]$. The incremental exercise test consisted of a steady-state resting period of at least $3 \mathrm{~min}$, followed by $3 \mathrm{~min}$ of load-less pedalling with subsequent systematic increases in work rate, i.e. stepwise increments of $10 \mathrm{~W}$ each minute, starting at $10 \mathrm{~W}$. $W \max$ was defined as the greatest work rate that the subject was able to maintain for $\geqslant 30 \mathrm{~s}$. Constant-load exercise tests consisted of a steady-state resting period, a 1-min period of load-less pedalling and then an immediate increase in work rate to $75 \% W \max$. ET was recorded as the time from the increase in work rate to $75 \% \mathrm{~W} \max$ to the point of symptom limitation. Across centres, various cardiopulmonary exercise testing systems (SensorMedics, Yorba Linda, CA, USA; MedGraphics, St Paul, MN, USA; VIASYS Healthcare GmbH, Hoechberg, Germany) were used to collect breath-by-breath measurements. These measurements were recorded as 30-s averages: 1) "rest" was defined as the end of the steady-state resting period; 2) exercise data were assessed during the third 30-s period of each 2-min interval of loaded exercise; and 3) end of exercise "peak" values were defined as the average over the last $30 \mathrm{~s}$ of loaded exercise. At rest, within the last 30-s period of each 2-min interval during exercise, and at the end of exercise, subjects rated the intensity of their breathing discomfort using the modified Borg scale [21] and then performed an IC manoeuvre.

Three main time-points were used for evaluation of exercise parameters, i.e. pre-exercise rest, isotime and peak exercise. "Isotime" was defined as the duration of the shortest exercise test on days $-5,0,21$ and 42 . Values at isotime were measured directly at the end of the shortest exercise test and were derived by linear interpolation between the two values before and after the 2-min interval containing this time during the longer exercise tests. Changes in exercise parameters, measured at rest, isotime and peak exercise on days 0,21 and 42 from pretreatment exercise baseline on day -5 , were compared between treatment groups. To evaluate exercise-induced changes independently of resting values, "exercise responses" (e.g. dynamic hyperinflation) were calculated as changes from rest during exercise. 


\section{Analysis}

The conventional level of statistical significance $(\mathrm{p}<0.05)$ was used for all analyses. Assuming a treatment difference in the primary endpoint, ET on day 42, of $120 \pm 284$ s [6], sample size calculations estimated a need for $\geqslant 89$ patients per treatment arm using a two-tailed t-test with $\alpha=0.05, \beta=0.20$. The primary endpoint was subjected to confirmatory statistics using analysis of covariance (ANCOVA) with a pre-specified pretreatment exercise baseline on day -5 as covariate, and treatment and centre as main effects. Possible treatment-bycentre interactions were first considered and assessed in the model. Secondary endpoints were evaluated in an exploratory analysis using the same main effect model. Results are reported as means \pm SD or percentages, where appropriate. Treatment differences are presented as least square means \pm SE, and corresponding p-values taken from ANCOVA. Pearson's correlations were performed in order to examine the strength of the relationship between changes in lung hyperinflation, exertional dyspnoea and ET in response to treatment.

\section{Results}

\section{Subjects}

Of the 198 patients randomised (98 tiotropium, 100 placebo), 187 patients (96 tiotropium, 91 placebo) completed at least 18 days of treatment and were included in the intentto-treat analysis (table 1). Nine of the missing 11 randomised patients belonged to the placebo group. Worsening of disease under study was the reason for discontinuation in seven of these nine subjects.
At study entry, groups were well matched for sex, age, body size, pulmonary function and exercise capacity (table 1). Prestudy use of respiratory medications was also well balanced between groups. Incremental $W$ max ranged 10-190 W, with similar mean values in the tiotropium and placebo groups (table 1). Physiological parameters measured at end-exercise were similar for the symptom-limited incremental and baseline constant-load exercise tests (table 1). Measurements during baseline constant-load exercise tests were also comparable across groups (table 2).

\section{Effects of tiotropium on resting lung function}

Improvements in spirometric parameters following treatment with tiotropium were consistent with previous studies (table 3) [11, 12, 22]. The present study extended these observations by also evaluating the effects of tiotropium on lung volumes measured by body plethysmography (table 3). Trough and peak responses of FRC and residual volume (RV) demonstrated significantly reduced lung hyperinflation in the tiotropium group versus placebo group at all time points (table 3). Peak responses of TLC on days 0 and 42, and trough responses on day 42 , reached statistical significance in patients receiving tiotropium as compared with placebo $(\mathrm{p}<0.05)$ (table 3).

\section{Effects of tiotropium on endurance time at $75 \% \mathrm{~W}$ max}

ANCOVA revealed no significant treatment-by-centre interactions.

In the tiotropium group, ET increased significantly from

Table 1. - Subject characteristics at study entry (day -15) and at pretreatment baseline (pulmonary function: pre-dose on day 0; exercise: day -5)

\begin{tabular}{|c|c|c|c|c|}
\hline & \multicolumn{2}{|c|}{ Tiotropium } & \multicolumn{2}{|c|}{ Placebo } \\
\hline & Study entry & Baseline & Study entry & Baseline \\
\hline Subjects n & \multicolumn{2}{|c|}{96} & \multicolumn{2}{|c|}{91} \\
\hline Sex, M:F & \multicolumn{2}{|c|}{$68: 28$} & \multicolumn{2}{|c|}{$70: 21$} \\
\hline Age yrs & \multicolumn{2}{|c|}{$61.5 \pm 5.9$} & \multicolumn{2}{|c|}{$59.4 \pm 8.0$} \\
\hline Body mass index $\mathrm{kg} \cdot \mathrm{m}^{-2}$ & \multicolumn{2}{|c|}{$26.8 \pm 4.6$} & \multicolumn{2}{|c|}{$26.2 \pm 5.0$} \\
\hline Smoking history pack-yrs & \multicolumn{2}{|c|}{$50.2 \pm 22.4$} & \multicolumn{2}{|c|}{$52.1 \pm 30.7$} \\
\hline Current smokers n & \multicolumn{2}{|c|}{37} & \multicolumn{2}{|c|}{42} \\
\hline \multicolumn{5}{|l|}{ Pulmonary function } \\
\hline$D \mathrm{~L}, \mathrm{CO} \mathrm{mL} \cdot \mathrm{min}^{-1} \cdot \mathrm{mmHg}^{-1}(\%$ pred $)$ & $15.0 \pm 5.7(56 \pm 19)$ & & $15.4 \pm 5.9(56 \pm 20)$ & \\
\hline FEV1 L ( $\%$ pred $)$ & $1.22 \pm 0.45(41 \pm 13)$ & $1.25 \pm 0.46(42 \pm 13)$ & $1.27 \pm 0.45(41 \pm 12)$ & $1.29 \pm 0.45(42 \pm 12)$ \\
\hline FVC L ( $\%$ pred $)$ & $2.64 \pm 0.82(71 \pm 16)$ & $2.73 \pm 0.80(74 \pm 17)$ & $2.79 \pm 0.81(73 \pm 17)$ & $2.92 \pm 0.86(75 \pm 17)$ \\
\hline $\mathrm{FEV} 1 / \mathrm{FVC} \%$ & $46.2 \pm 9.9$ & $45.7 \pm 10.3$ & $45.5 \pm 9.4$ & $44.6 \pm 9.4$ \\
\hline SGaw $1 \cdot \mathrm{cmH}_{2} \mathrm{O}^{-1} \cdot \mathrm{s}^{-1}$ & $0.036 \pm 0.021$ & $0.038 \pm 0.026$ & $0.037 \pm 0.023$ & $0.036 \pm 0.017$ \\
\hline IC L & $2.23 \pm 0.78$ & $2.19 \pm 0.69$ & $2.20 \pm 0.68$ & $2.18 \pm 0.62$ \\
\hline FRC L (\% pred) & $5.27 \pm 1.00(161 \pm 30)$ & $5.30 \pm 1.04(161 \pm 28)$ & $5.37 \pm 1.24(160 \pm 30)$ & $5.37 \pm 1.16(160 \pm 29)$ \\
\hline TLC L ( $\%$ pred $)$ & $7.51 \pm 1.34(120 \pm 17)$ & $7.49 \pm 1.34(120 \pm 18)$ & $7.57 \pm 1.42(118 \pm 15)$ & $7.54 \pm 1.37(118 \pm 15)$ \\
\hline RV L (\% pred) & $4.49 \pm 0.94(199 \pm 42)$ & $4.42 \pm 0.99(197 \pm 43)$ & $4.45 \pm 1.21(197 \pm 48)$ & $4.37 \pm 1.11(196 \pm 48)$ \\
\hline \multicolumn{5}{|l|}{ Peak exercise $^{\#}$} \\
\hline Work rate $\mathrm{W}$ & $78 \pm 32$ & $59 \pm 24$ & $79 \pm 30$ & $60 \pm 22$ \\
\hline$V^{\prime} \mathrm{O}_{2} \mathrm{~L} \cdot \min ^{-1}$ & $1.26 \pm 0.45$ & $1.22 \pm 0.42$ & $1.28 \pm 0.35$ & $1.26 \pm 0.36$ \\
\hline$V^{\prime} \mathrm{O}_{2} \mathrm{~mL} \cdot \mathrm{kg}^{-1} \cdot \mathrm{min}^{-1}$ & $16.0 \pm 4.6$ & $15.5 \pm 4.3$ & $16.7 \pm 4.3$ & $16.4 \pm 4.5$ \\
\hline Heart rate beats $\cdot \min ^{-1}$ & $123 \pm 19$ & $120 \pm 19$ & $127 \pm 20$ & $125 \pm 20$ \\
\hline$V^{\prime} \mathrm{E} \mathrm{L} \cdot \mathrm{min}^{-1}$ & $42.3 \pm 15.7$ & $41.4 \pm 13.7$ & $44.3 \pm 13.7$ & $44.2 \pm 14.6$ \\
\hline $\mathrm{Sa}, \mathrm{O}_{2} \%$ & & $92.7 \pm 4.6$ & & $93.5 \pm 3.7$ \\
\hline
\end{tabular}

Data are presented as mean \pm SD unless otherwise stated. M: male; F: female; $D$ L,CO: diffusing capacity for carbon monoxide; FEV1: forced expiratory volume in one second; FVC: forced vital capacity; SGaw: specific airway conductance; IC: inspiratory capacity; FRC: functional residual capacity; TLC: total lung capacity; RV: residual volume; $V^{\prime} \mathrm{O}_{2}$ : oxygen consumption; $V^{\prime} \mathrm{E}$ : minute ventilation; $S \mathrm{~S}$, $\mathrm{O}_{2}$ : oxygen saturation measured by pulse oximetry. "\#: symptom-limited incremental exercise at study entry and constant-load exercise at baseline (measurements are averages of the last $30 \mathrm{~s}$ of loaded exercise). 
Table 2. - Baseline (day -5) measurements during constantload exercise at $75 \%$ maximal work capacity ( $\left.W_{\max }\right)$

\begin{tabular}{lcc}
\hline & Tiotropium & Placebo \\
\hline Subjects n & 96 & 91 \\
Work rate W & $59 \pm 24$ & $60 \pm 22$ \\
Endurance time s & $467 \pm 270$ & $517 \pm 310$ \\
$V^{\prime}$ E L·min & \\
$\quad$ Rest & $13.2 \pm 3.5$ & \\
$\quad$ Isotime & $40.5 \pm 13.8$ & $13.3 \pm 3.5$ \\
$\quad$ Peak & $41.4 \pm 13.7$ & $42.7 \pm 14.4$ \\
fR breaths·min & & $44.2 \pm 14.6$ \\
$\quad$ Rest & $18.2 \pm 4.5$ & \\
$\quad$ Isotime & $29.9 \pm 5.8$ & $18.4 \pm 4.8$ \\
$\quad$ Peak & $30.9 \pm 5.8$ & $29.4 \pm 6.5$ \\
$V$ T L & & $30.8 \pm 6.8$ \\
$\quad$ Rest & $0.76 \pm 0.23$ & \\
Isotime & $1.38 \pm 0.45$ & $0.76 \pm 0.27$ \\
$\quad$ Peak & $1.36 \pm 0.43$ & $1.48 \pm 0.47$ \\
IC L & & $1.46 \pm 0.46$ \\
$\quad$ Rest & $2.25 \pm 0.68$ & \\
Isotime & $1.85 \pm 0.60$ & $2.33 \pm 0.62$ \\
$\quad$ Peak & $1.80 \pm 0.61$ & $1.94 \pm 0.56$ \\
IRV L & & $1.92 \pm 0.55$ \\
$\quad$ Rest & $1.49 \pm 0.62$ & $1.56 \pm 0.56$ \\
Isotime & $0.46 \pm 0.33$ & $0.47 \pm 0.32$ \\
Peak & $0.43 \pm 0.40$ & $0.46 \pm 0.33$ \\
Dyspnoea Borg & & \\
$\quad$ Rest & $0.9 \pm 1.1$ & $0.7 \pm 0.9$ \\
Isotime & $6.2 \pm 2.4$ & $6.4 \pm 2.1$ \\
$\quad$ Peak & $6.8 \pm 2.3$ & \\
\hline
\end{tabular}

Data are presented as mean $\pm \mathrm{SD} . V^{\prime} \mathrm{E}$ : minute ventilation; $f \mathrm{R}$ : breathing frequency; $V \mathrm{~T}$ : tidal volume; IC: inspiratory capacity; IRV: inspiratory reserve volume.

the baseline on day -5 by $99 \pm 192$ s $(31 \%)$ after the first dose of trial medication, with further increases after 21 days (by $121 \pm 197 \mathrm{~s}$ or $36 \%$ over baseline) and 42 days of treatment (by $162 \pm 267 \mathrm{~s}$ or $49 \%$ over baseline, all $\mathrm{p}<0.0001$ ) (fig. 1 ). The tendency for a progressive increase in ET from day 21 to day 42 of treatment with tiotropium did not reach statistical significance $(\mathrm{p}=0.074)$.

In the placebo group, mean ET increased from baseline by $52 \pm 198 \mathrm{~s}$ or $17 \%$ after the first dose of trial medication $(\mathrm{p}=0.016)$ and returned to a level not significantly different from baseline during the subsequent 42-day treatment period.

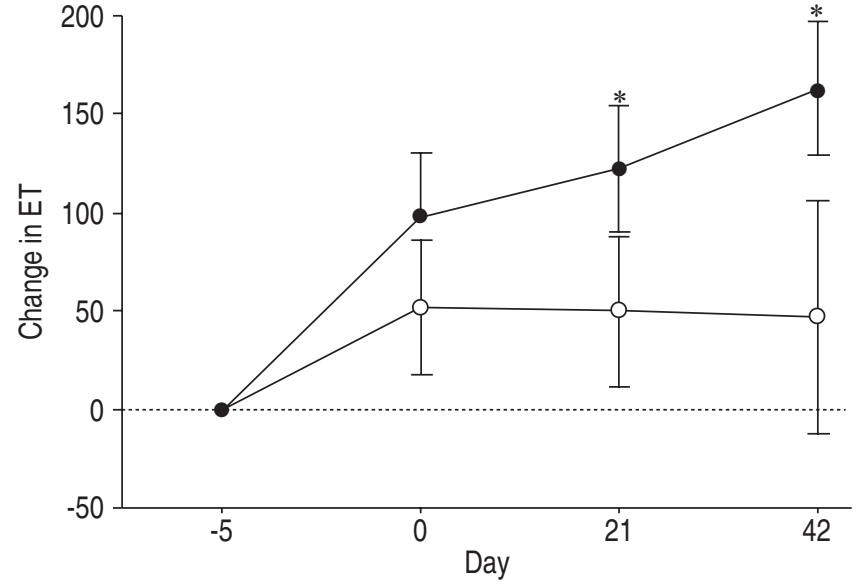

Fig. 1.-Changes in constant-load exercise endurance time (ET) are shown from baseline (day -5) for placebo $(\bigcirc)$ and tiotropium $(\bullet)$. Data are presented as mean \pm SEM. $*$ : $\mathrm{p}<0.05$ between groups.

Mean change from baseline was still significant after 21 days $(\mathrm{p}=0.038)$ but not after 42 days $(\mathrm{p}=0.158)$ of treatment (fig. 1).

The mean difference in ET of $40 \mathrm{~s}$, between tiotropium and placebo after the first dose of trial medication, did not reach statistical significance $(\mathrm{p}=0.15$, table 4$)$. There was a statistically significant difference in ET between tiotropium and placebo after 21 days $(67 \mathrm{~s}, \mathrm{p}=0.039,13.6 \%$ difference) and after 42 days of treatment ( $105 \mathrm{~s}, \mathrm{p}=0.0098,21.4 \%$ difference).

\section{Effects of tiotropium on exertional dyspnoea}

In both the tiotropium and placebo groups, mean resting dyspnoea did not change from baseline at any time-point (between "very, very slight" and "very slight" prior to all exercise tests; fig. 2). Dyspnoea intensity at the point of symptom limitation was not different from baseline in both groups (between "severe" and "very severe"); however, patients in the tiotropium group exercised for longer before reaching the same degree of dyspnoea as patients in the placebo group.

In the tiotropium group, exercise-related dyspnoea was lower during treatment as compared with baseline: at isotime (mean=6 min $48 \mathrm{~s}$ ), Borg ratings of dyspnoea intensity fell

Table 3. - Treatment differences in lung function parameters for the tiotropium group as compared to the placebo group

\begin{tabular}{|c|c|c|c|c|c|}
\hline & \multicolumn{2}{|c|}{ Trough Response } & \multicolumn{3}{|c|}{ Peak Response } \\
\hline & Day 21 & Day 42 & Day 0 & Day 21 & Day 42 \\
\hline FEV1 L & $0.10 \pm 0.03 * * *$ & $0.12 \pm 0.03 * * *$ & $0.17 \pm 0.02^{\#}$ & $0.22 \pm 0.03^{\#}$ & $0.22 \pm 0.04^{\#}$ \\
\hline FVC L & $0.19 \pm 0.06^{* * *}$ & $0.25 \pm 0.06^{\#}$ & $0.37 \pm 0.04^{\#}$ & $0.41 \pm 0.06^{\#}$ & $0.43 \pm 0.06^{\#}$ \\
\hline FEV1/FVC \% & $0.8 \pm 0.6$ & $0.3 \pm 0.6$ & $0.5 \pm 0.6$ & $1.5 \pm 0.7 *$ & $1.4 \pm 0.8$ \\
\hline SGaw $1 \cdot \mathrm{cmH}_{2} \mathrm{O}^{-1} \cdot \mathrm{sec}^{-1}$ & $0.015 \pm 0.006^{*}$ & $0.006 \pm 0.002 * *$ & $0.016 \pm 0.002^{\#}$ & $0.029 \pm 0.007^{\#}$ & $0.022 \pm 0.003^{\#}$ \\
\hline $\mathrm{IC} \mathrm{L}$ & $0.10 \pm 0.05^{*}$ & $0.10 \pm 0.05^{*}$ & $0.20 \pm 0.04^{\#}$ & $0.25 \pm 0.06^{* * *}$ & $0.24 \pm 0.06^{* * *}$ \\
\hline RV L & $-0.23 \pm 0.10^{*}$ & $-0.36 \pm 0.09 * * *$ & $-0.50 \pm 0.08^{\#}$ & $-0.51 \pm 0.10^{\#}$ & $-0.56 \pm 0.10^{\#}$ \\
\hline FRC L & $-0.17 \pm 0.08^{*}$ & $-0.30 \pm 0.08 * * *$ & $-0.41 \pm 0.07^{\#}$ & $-0.41 \pm 0.08^{\#}$ & $-0.45 \pm 0.08^{\#}$ \\
\hline RV/TLC \% & $-2.2 \pm 0.8 * *$ & $-3.0 \pm 0.8 * * *$ & $-4.9 \pm 0.6^{\#}$ & $-5.8 \pm 0.9^{\#}$ & $-6.0 \pm 0.9^{\#}$ \\
\hline FRC/TLC \% & $-1.6 \pm 0.6^{* *}$ & $-2.1 \pm 0.6^{* * *}$ & $-3.5 \pm 0.5^{\#}$ & $-3.9 \pm 0.7^{\#}$ & $-4.0 \pm 0.7^{\#}$ \\
\hline TLC L & $-0.07 \pm 0.08$ & $-0.20 \pm 0.08^{*}$ & $-0.21 \pm 0.08^{* *}$ & $-0.15 \pm 0.09$ & $-0.19 \pm 0.09^{*}$ \\
\hline
\end{tabular}

Data are presented as tiotropium-placebo, means adjusted for centre and baseline \pm SE. FEV1: forced expiratory volume in one second; FVC: forced vital capacity; SGaw: specific airway conductance; IC: inspiratory capacity; RV: residual volume; FRC: functional residual capacity; TLC: total lung capacity. *: $\mathrm{p}<0.05 ; * * \mathrm{p}<0.01 ; * * *: \mathrm{p}<0.001 ;{ }^{\#}: \mathrm{p}<0.0001$. 
Table 4.-Treatment differences in exercise test parameters for the tiotropium group compared with the placebo group

\begin{tabular}{|c|c|c|c|}
\hline & Day 0 & Day 21 & Day 42 \\
\hline Endurance time s & $40 \pm 28$ & $67 \pm 32 *$ & $105 \pm 40 * *$ \\
\hline \multicolumn{4}{|l|}{ Rest } \\
\hline Dyspnoea Borg & $-0.1 \pm 0.1$ & $0.0 \pm 0.1$ & $-0.1 \pm 0.1$ \\
\hline $\mathrm{IC} \mathrm{L}$ & $0.25 \pm 0.04^{\#}$ & $0.21 \pm 0.04^{\#}$ & $0.23 \pm 0.05^{\#}$ \\
\hline$V \mathrm{~T} \mathrm{~L}$ & $0.03 \pm 0.02$ & $-0.02 \pm 0.02$ & $0.00 \pm 0.03$ \\
\hline$f \mathrm{R}$ breaths $\cdot \mathrm{min}^{-1}$ & $0.2 \pm 0.4$ & $0.6 \pm 0.5$ & $0.6 \pm 0.5$ \\
\hline$V^{\prime} \mathrm{E} \mathrm{L} \cdot \mathrm{min}^{-1}$ & $0.2 \pm 0.4$ & $0.2 \pm 0.4$ & $0.4 \pm 0.4$ \\
\hline IRV L & $0.22 \pm 0.05^{\#}$ & $0.23 \pm 0.05^{\#}$ & $0.23 \pm 0.05^{\#}$ \\
\hline \multicolumn{4}{|l|}{ Isotime exercise } \\
\hline Dyspnoea Borg & $-0.5 \pm 0.2 *$ & $-0.7 \pm 0.3^{*}$ & $-0.9 \pm 0.3 * *$ \\
\hline $\mathrm{IC} \mathrm{L}$ & $0.21 \pm 0.04^{\#}$ & $0.19 \pm 0.05^{\#}$ & $0.18 \pm 0.05^{* * *}$ \\
\hline$V \mathrm{~T} \mathrm{~L}$ & $0.09 \pm 0.03^{* * *}$ & $0.15 \pm 0.03^{\#}$ & $0.11 \pm 0.03 * * *$ \\
\hline$f \mathrm{R}$ breaths $\cdot \min ^{-1}$ & $-0.6 \pm 0.5$ & $-0.7 \pm 0.6$ & $-0.5 \pm 0.6$ \\
\hline$V^{\prime} \mathrm{E} \mathrm{L} \cdot \mathrm{min}^{-1}$ & $1.8 \pm 0.7 *$ & $3.3 \pm 1.1 * *$ & $3.0 \pm 0.8^{* * *}$ \\
\hline IRV L & $0.13 \pm 0.04 * * *$ & $0.08 \pm 0.04 *$ & $0.08 \pm 0.04^{*}$ \\
\hline \multicolumn{4}{|l|}{ Peak exercise } \\
\hline Dyspnoea Borg & $-0.2 \pm 0.2$ & $-0.1 \pm 0.2$ & $-0.1 \pm 0.3$ \\
\hline $\mathrm{IC} \mathrm{L}$ & $0.15 \pm 0.04 * * *$ & $0.22 \pm 0.05^{\#}$ & $0.15 \pm 0.05^{* *}$ \\
\hline$V \mathrm{~T} \mathrm{~L}$ & $0.10 \pm 0.03^{* * *}$ & $0.11 \pm 0.03 * * *$ & $0.10 \pm 0.03 * * *$ \\
\hline$f \mathrm{R}$ breaths $\cdot \min ^{-1}$ & $0.10 \pm 0.48$ & $0.33 \pm 0.50$ & $0.59 \pm 0.54$ \\
\hline$V^{\prime} \mathrm{E} \mathrm{L} \cdot \min ^{-1}$ & $2.9 \pm 0.8 * * *$ & $4.0 \pm 1.1 * * *$ & $4.1 \pm 0.7^{\#}$ \\
\hline IRV L & $0.07 \pm 0.04$ & $0.14 \pm 0.05^{* *}$ & $0.07 \pm 0.05$ \\
\hline
\end{tabular}

Data are presented as tiotropium-placebo, means adjusted for centre and baseline \pm SE; IC: inspiratory capacity; $V \mathrm{~T}$ : tidal volume; $f \mathrm{R}$ : breathing frequency; $V^{\prime} \mathrm{E}$ : minute ventilation; IRV: inspiratory reserve volume; *: $\mathrm{p}<0.05$; $^{* *}: \mathrm{p}<0.01 ;{ }^{* * *} \mathrm{p}<0.001{ }^{*}: \mathrm{p}<0.0001$.

from a baseline level of $6.2 \pm 2.4$, between severe and very severe, to $5.2 \pm 2.2$ after the first dose of trial medication $(\mathrm{p}<0.0001), 5.2 \pm 2.3$ after 21 days of treatment $(\mathrm{p}=0.0002)$ and $4.8 \pm 2.2$ after 42 days of treatment $(\mathrm{p}<0.0001)$ (fig. 2). During treatment with placebo, dyspnoea intensity at isotime (mean=6 $\min 47 \mathrm{~s}$ ) fell significantly from a baseline level of $5.4 \pm 2.2$ to $4.8 \pm 1.9$, only after the first dose of trial medication $(\mathrm{p}=0.004)$, but was not significantly different from baseline after 21 and 42 days of treatment $(5.0 \pm 2.1$ and $4.8 \pm 2.1$, respectively). The change from baseline in dyspnoea intensity at isotime in the tiotropium group was significantly greater than the change from baseline in the placebo group at all time-points, with a difference of $0.5 \pm 0.2$ Borg units after the first dose $(\mathrm{p}=0.042), 0.7 \pm 0.3$ Borg units after 21 days of treatment $(\mathrm{p}=0.026)$ and $0.9 \pm 0.3$ Borg units after 42 days of treatment $(\mathrm{p}=0.0075)$.

\section{Effects of tiotropium on operating lung volumes and ventilatory responses to exercise}

Ventilatory responses to exercise were similar in both groups at baseline (table 2); the tiotropium and placebo groups experienced a similar extent of dynamic hyperinflation resulting from exercise, i.e. decrease in IC from resting levels (table 2, fig. 3). Compared with placebo, mean changes from baseline of IC at rest, isotime and end-exercise were significantly higher by $150-250 \mathrm{~mL}$ at all time-points after treatment with tiotropium $(\mathrm{p}<0.01$, table 4$)$. However, the magnitude of increase in EELV (decrease in IC) during exercise did not change during maintenance treatment with tiotropium, as compared with placebo (fig. 3).

In response to 42 days of treatment with tiotropium, there were significant increases in $V \mathrm{~T}$ at isotime (table 4) from baseline, as compared with placebo $(\mathrm{p}=0.0001)$. The concurrent change in breathing frequency was not significantly different from placebo, such that minute ventilation $\left(V^{\prime} \mathrm{E}\right)$ increased in the tiotropium group when compared with placebo $(p=0.0004)$. Since the increase in IC at isotime in the tiotropium group was greater than the increase in $V \mathrm{~T}$, inspiratory reserve volume (IRV) at isotime was also increased from baseline after 42 days of treatment, as compared with placebo $(\mathrm{p}=0.029)$. At all time-points during treatment, increases in end-exercise $V^{\prime} \mathrm{E}$ and $V \mathrm{~T}$ were significantly greater after tiotropium as compared with placebo (table 4).

\section{Correlates of improvements in exertional dyspnoea and endurance time}

Within the tiotropium group $(n=96)$, the reduction in exertional dyspnoea intensity at isotime (BorgISO) correlated with the improvement in exercise ET $(r=-0.61, p<0.0001)$. The increase in IC at isotime during exercise was a good correlate of the increase in $\operatorname{ET}(r=0.53, p=0.0001)$ and the decrease in exertional dyspnoea intensity (BorgISO, $\mathrm{r}=-0.53, \mathrm{p}=0.0001$; fig. 4).

b)

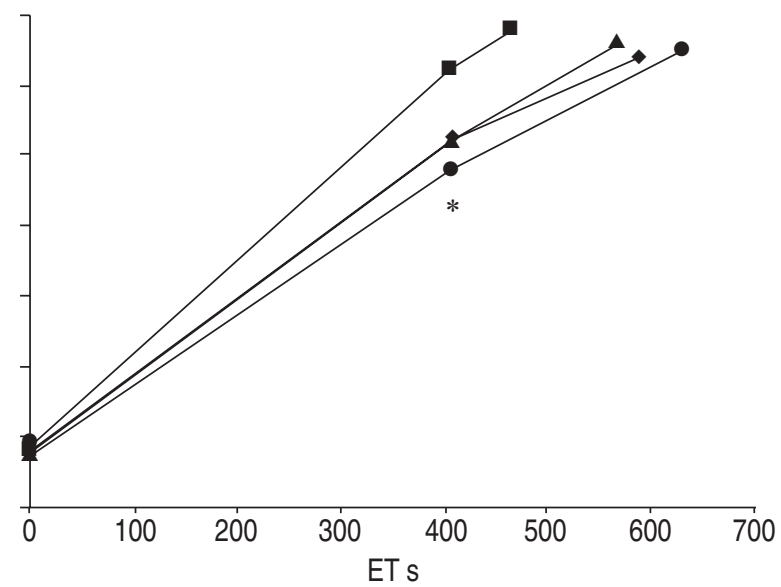

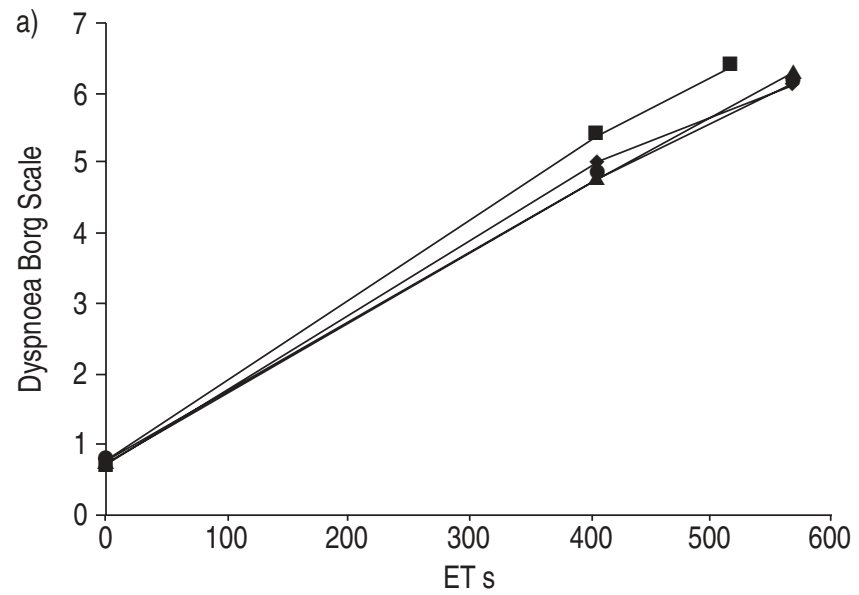

Fig. 2. - Intensity of dyspnoea ("breathing discomfort") during constant-load cycle exercise was significantly reduced at isotime after treatment with tiotropium (b) as compared to placebo (a). Tiotropium allowed patients to exercise significantly longer before reaching the same level of intolerable dyspnoea. ET: exercise endurance time; $\mathbf{\square}$ : day $-5 ; \boldsymbol{\Delta}$ : day $0 ; \bullet$ : day 21 ; $\bullet$ : day 42 . ${ }^{*}: \mathrm{p}<0.05$ during treatment (days 0,21 and 42 ) as compared to baseline (day -5). 

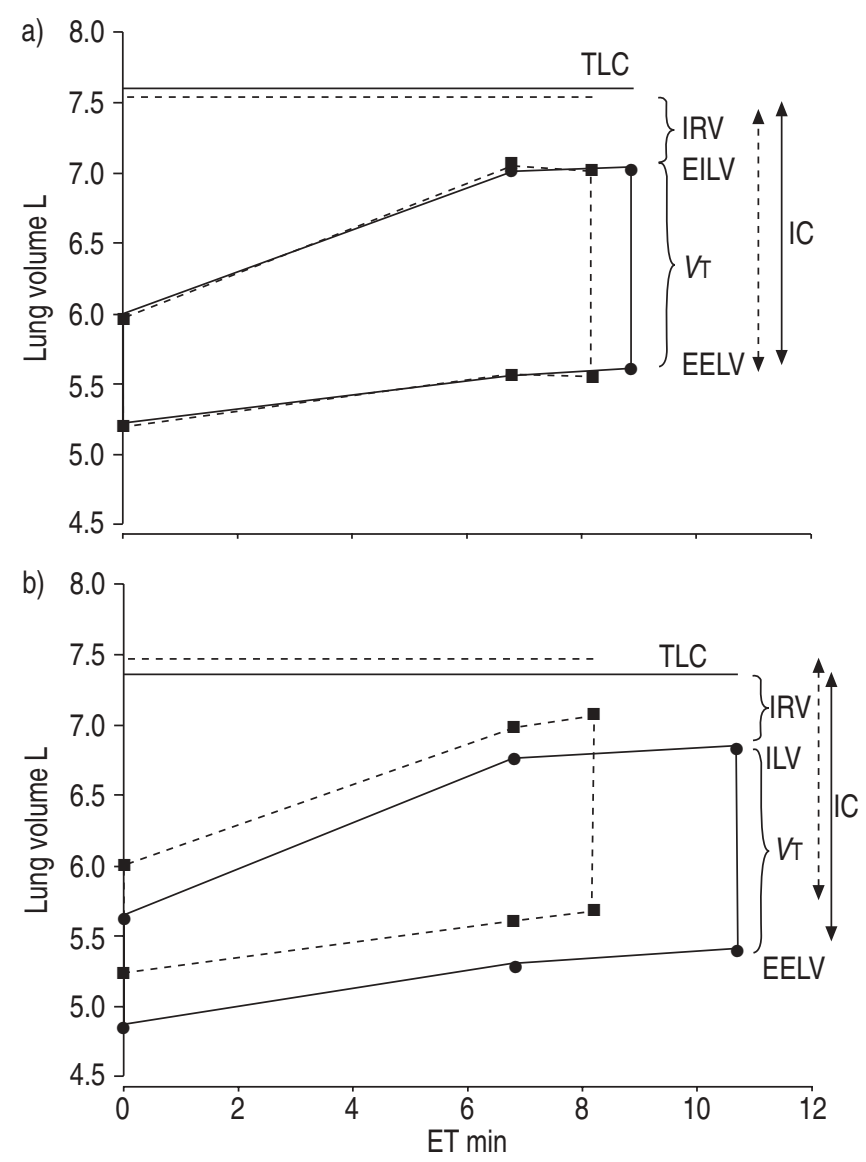

Fig. 3.-Operating lung volumes at rest and during exercise at baseline (---) and after 42 days (-) of treatment with placebo (a; $\mathrm{n}=91$ ) and tiotropium ( $\mathrm{b} ; \mathrm{n}=96$ ). TLC: total lung capacity; IRV: inspiratory reserve volume; EILV: end-inspiratory lung volume; $V \mathrm{~T}$ : tidal volume; EELV: end-expiratory lung volume; IC: inspiratory capacity.

\section{Effects on chronic activity-related dyspnoea and rescue medication}

At baseline, patients experienced a moderate degree of activity-related dyspnoea, with a mean BDI focal score of 6.3 in both treatment groups. Changes from baseline expressed as

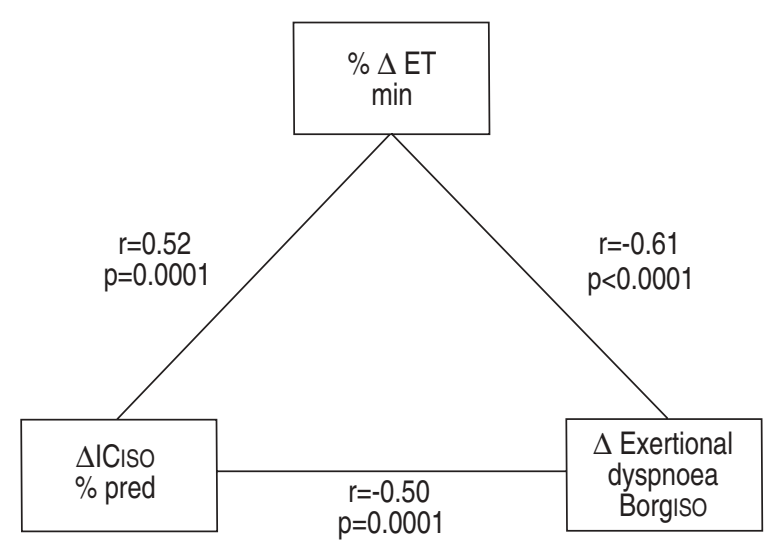

Fig. 4.-Inter-relationships between improvements in response to treatment with tiotropium $(\mathrm{n}=96)$, i.e. differences $(\Delta)$ calculated as values at day 42 minus values at day -5 baseline. ET: endurance time; BorgISO: exertional dyspnoea intensity at isotime; ICISO: inspiratory capacity at isotime; $\%$ pred: $\%$ predicted.
TDI focal scores were significantly better in the tiotropium group, as compared with the placebo group, by 1.8 and 1.7 units after 21 and 42 days of treatment, respectively $(\mathrm{p}=0.0001)$. After 42 days of treatment, TDI focal scores were $2.1 \pm 3.0$ and $0.5 \pm 2.5$ in the tiotropium and placebo groups, respectively $(\mathrm{p}<0.001)$. Change from baseline was significant in the tiotropium ( $\mathrm{p}=0.0001)$, but not in the placebo group.

The daytime use of salbutamol for symptomatic relief also provides an indication of the degree of dyspnoea experienced during daily activities. Daytime use of salbutamol was significantly reduced in the tiotropium group as compared with the placebo group during each of the 6 weeks of treatment; the mean difference in the weekly average ranged $-1.0-1.3$ puffs $\cdot$ day $^{-1}(\mathrm{p}<0.0002)$.

\section{Adverse events}

The overall incidence of adverse events (tiotropium 36.7\%, placebo $41.0 \%$ ) and the number of patients experiencing serious adverse events (tiotropium 3.1\%, placebo 3.0\%) were similar in both treatment groups. COPD exacerbations were experienced by 7.1 and $12.0 \%$ of patients in the tiotropium and placebo groups, respectively $(\mathrm{p}=0.34)$. No exercise-related serious adverse events were reported during the 1,237 cycle exercise tests performed in this study.

\section{Discussion}

The major findings of this study were that treatment with the long-acting anticholinergic tiotropium was associated with: 1) a sustained reduction in plethysmographic FRC throughout the period of the study; 2) statistically significant improvements in exertional dyspnoea and in exercise endurance that persisted over a 6-week period; and 3) a decrease in operating lung volumes at rest and throughout exercise, which thereby reduced mechanical restriction, increased $V \mathrm{~T}$ expansion and improved ventilatory capacity. In addition, a correlation analysis showed close inter-relationships between improved IC, reduced exertional dyspnoea and improved exercise endurance during treatment with tiotropium.

\section{Effect of tiotropium on resting lung volumes}

In agreement with previous studies, tiotropium treatment resulted in consistent improvements in trough FEV1 over placebo with little or no change in the FEV1/forced vital capacity (FVC) ratio [11-13]. Therefore, the changes in FEV1 mainly reflect the increase in FVC. Increased vital capacity (VC) is inversely related to decreased RV, which occurs as a result of more complete lung emptying [23, 24].

This study extended the results of previous studies on tiotropium [11-13, 25] by demonstrating consistent improvements in the trough resting IC with inverse reductions in plethysmographic FRC (table 3). In severe COPD, EELV is a continuous dynamic variable and its level is influenced by the extent of expiratory flow limitation, the breathing pattern and the prevailing $V^{\prime} \mathrm{E}[23,24]$. Thus, in many patients with COPD during quiet tidal breathing, inspiration begins before expiration is complete and volume fails to decline to its static equilibrium point. The immediate reduction of FRC after the first dose of tiotropium (day 0) confirms that cholinergic bronchomotor tone contributed to expiratory flow limitation and the regulation of dynamic EELV in these patients. Tiotropium would be expected to increase tidal expiratory flow rates, which, when integrated over time, would reduce the 
dynamic EELV to a value closer to the respiratory system's relaxation volume. This view is supported by significantly greater trough and peak responses of specific airway conductance after tiotropium, as compared with placebo $(\mathrm{p}<0.05$, table 3$)$. The larger IC (and smaller EELV) means that the required alveolar ventilation at rest could be achieved at lower operating volumes after treatment with tiotropium, as compared to placebo. This, in turn, has favourable implications for muscle function and dynamic mechanics when the respiratory system is stressed as, for example, during exercise.

Furthermore, this study confirms the results of two previous population studies that have shown small $(\sim 0.2 \mathrm{~L})$, but consistent, reductions in plethysmographic TLC following bronchodilators [26, 27]. In a proportion of patients the change in IC, therefore, underestimated the actual reduction in EELV. The mechanisms of TLC reduction (changes in IC and FRC) were not ascertained in this study and remain speculative. Given the heterogeneous pathophysiology in COPD, bronchodilator effects on the respiratory system's elastic properties are likely to be variable, and it would be unlikely that decreased lung compliance alone (on a regional basis) could explain the observed reductions in TLC. Alternatively, reductions in plethysmographic TLC may reflect measurement artefact. In severe COPD, swings in mouth pressure during panting can underestimate true swings in alveolar pressures, leading to an overestimation of the measured FRC and TLC [28]. In this study, panting frequency was set at $1 \mathrm{~Hz}$, which would minimise this effect [29]. However, the possibility that small reductions in TLC after bronchodilator therapy may simply indicate a reduced disparity between mouth and alveolar pressures as compared with the baseline condition cannot be excluded.

\section{Effect of tiotropium on exercise performance}

During both incremental and endurance exercise testing at baseline, patients experienced severe exertional dyspnoea, and peak symptom-limited $V^{\prime} \mathrm{O}_{2}$ averaged only $16 \mathrm{~mL} \cdot \mathrm{kg}^{-1} \cdot \mathrm{min}^{-1}$ (table 1). As expected, serious ventilatory constraints during incremental and constant-load exercise were evident; peak ventilation averaged $43 \mathrm{~L} \cdot \mathrm{min}^{-1}$ or $95 \%$ of the estimated maximal ventilatory capacity [30]. At the end of constant-load exercise, IC diminished by $18 \%$ of its already reduced resting value and IRV was markedly reduced by $71 \%$ to an average of $0.44 \mathrm{~L}$, indicating severe mechanical constraints on ventilation (table 2).

In the group receiving placebo, mean exercise ET increased initially on day 0 by $17 \%$ from pretreatment baseline, with no further increase thereafter. By contrast, within the tiotropium group, ET improved over the baseline value by $31 \%$ on day 0 , by $36 \%$ on day 21 , and by $49 \%$ on day 42 (fig. 1 ). The progressive numerical increase from day 21 to $42(\mathrm{p}=0.074)$ cannot be explained by time to pharmacodynamic steady state, which should be reached sooner. However, reduced operating lung volumes, reduced respiratory discomfort and increasing levels of daily activity are likely to be important contributors to the improved exercise performance following tiotropium.

The resting IC (not the VC) represents the true operating limits for $V \mathrm{~T}$ expansion during exercise and, therefore, influences maximal ventilatory capacity. DIAZ et al. [31] have shown that the resting IC ( $\%$ pred) correlated well with symptom-limited peak $V^{\prime} \mathrm{O}_{2}$ in patients with demonstrable expiratory flow limitation at rest. Similarly, good statistical correlations have recently been shown between the resting (and dynamic exercise) IC, the peak $V \mathrm{~T}$ and the peak symptom-limited $V^{\prime} \mathrm{O}_{2}$ in a large COPD population [8]. In the present study, similar correlations between the resting (and dynamic) IC and the peak $V \mathrm{~T}(\mathrm{r}=0.55, \mathrm{p}<0.0001)$, and the peak $V^{\prime} \mathrm{O}_{2}(\mathrm{r}=0.44, \mathrm{p}<0.0001)$ were seen during the prerandomisation constant-load exercise tests (day -5). Within both treatment groups together, peak $V^{\prime} \mathrm{O}_{2}$ at the end of constant-load exercise on day 42 also correlated well with the resting $\mathrm{IC}(\mathrm{r}=0.50, \mathrm{p}=0.0001)$, supporting the idea that exercise performance in COPD patients with and without bronchodilator therapy is determined, in part, by the degree of lung hyperinflation and the attendant mechanical restriction at rest. Bronchodilator-induced improvement in resting lung hyperinflation, therefore, results in increased exercise tolerance.

\section{Effects of tiotropium on operating lung volumes during exercise}

Adjusted for baseline, IC was significantly greater throughout exercise in the tiotropium group as compared to the placebo group, suggesting reduced operating lung volumes (table 4, fig. 3). In addition, IRV values were significantly higher at isotime in this group $(\mathrm{p}<0.05$, table 4 , fig. 3$)$ despite increased $V \mathrm{~T}$ expansion during constant-load exercise, indicating reduced mechanical restriction. The increased IC at rest and exercise probably occurred as a result of the increased tidal expiratory flow rates and lung emptying due to enhanced airway patency. Greater exercise $V \mathrm{~T}$ expansion in the setting of an unaltered breathing frequency resulted in small, but consistent, increases in both isotime and peak $V^{\prime} \mathrm{E}$ in the tiotropium group as compared to placebo (table 4). In accordance with a previous study, which examined the effects of ipratropium on exercise tolerance in COPD [6], acute reductions in IC from rest to end of exercise were similar in the active drug and placebo groups (i.e. a parallel downward shift in the IC-time slope; fig. 3). However, the fact that the rate and extent of this dynamic hyperinflation did not increase in the tiotropium group, despite increased cumulative ventilation over a longer duration of exercise, provides further proof of the drug's bronchodilator action throughout exercise.

\section{Effects of tiotropium on dyspnoea}

In contrast to the placebo group, a significant improvement in exertional dyspnoea at a standardised exercise load (isotime) was found in the tiotropium group (table 4, fig. 2). On day 42, the reduction in standardised Borg ratings was 0.9 unit with tiotropium, as compared to placebo. In a previous study, high-dose nebulised ipratropium bromide $(500 \mu \mathrm{g})$ resulted in a similar reduction in standardised Borg ratings [6]. Moreover, patients in the present study were capable of exercising for a longer duration at higher $V^{\prime} \mathrm{E}$ without any further increase in dyspnoea. Finally, there were parallel improvements in TDI, by an average of 1.7 units, as compared to placebo, indicating clinically relevant reductions in chronic activity-related dyspnoea and functional capacity [32, 33]. A further indication of a beneficial effect of tiotropium on dyspnoea was the reduced requirement for reliever shortacting bronchodilators throughout the course of the study in this group.

Consistent with previous studies [6, 34, 35], improvement in exertional dyspnoea following tiotropium correlated with the increased dynamic IC at isotime (fig. 4). Moreover, there was a good statistical correlation between improved exercise ET following tiotropium and the reduced Borg dyspnoea ratings at isotime. Bronchodilator-induced reductions in the resistive and elastic/threshold loads on the inspiratory muscles, together 
with their increased functional strength, would be expected to reduce the perceived contractile muscle effort for each breath resulting in improved exertional dyspnoea.

\section{Clinical significance of laboratory exercise testing results}

The degree of improvement in exercise ET (using the constant-load exercise protocol) that is judged to have clinical relevance is difficult to determine. Peak symptom-limited $V^{\prime} \mathrm{O}_{2}$ was almost identical during baseline incremental and constant-load testing, indicating that the latter, in fact, were "maximal" endurance tests. Clearly, COPD patients assigned to tiotropium were able to perform this demanding physical task with less respiratory discomfort (at standardised levels of exercise despite higher levels of ventilation) and over a longer duration. The magnitude of effect of tiotropium on ET and dyspnoea is comparable to that achieved using a similar exercise protocol with other proven dyspnoea-relieving interventions, such as oxygen [36], lung volume reduction surgery [37] and exercise training [38], suggesting a clinically important response. Improvements in the exertional dyspnoea ratings at isotime after 42 days of tiotropium occurred in tandem with the improved TDI, a measure of activity-related dyspnoea, again suggesting that acute improvements in the laboratory translate into important long-term effects in the home [32].

\section{Conclusions}

This study demonstrates the feasibility of conducting detailed exercise testing in a multicentre clinical trial setting, and is the first of its kind. It is important to note that these testing procedures can be conducted safely, as no exerciserelated serious adverse events were recorded during 1,237 exercise tests completed in these older, disabled patients. Tiotropium achieved sustained pharmacological lung volume reduction, and significant improvements in dyspnoea and exercise endurance that persisted over the 42-day treatment period. The present results support the hypothesis that lung hyperinflation, mechanical restriction, respiratory discomfort and exercise intolerance are closely linked in chronic obstructive pulmonary disease. The improvements in dyspnoea, ventilatory capacity and exercise performance are arguably clinically meaningful, and may help explain the improved overall health status previously documented following tiotropium therapy in such patients. An important clinical implication of this study is that the ability of this long-acting anticholinergic agent to enhance exercise performance could potentially be amplified by encouraging increased activity levels or, ideally, by enrolling such patients into a structured exercise programme.

Acknowledgements. The authors would like to thank the following investigators who participated in this trial: R. Casaburi, USA; P. Enright, USA; G. Ford, Canada; B. Interiano, USA; B.D. Johnson, USA; D. Köhler, Germany; H-J. Lepthin, Germany; I.M. Weisman, USA.

\section{References}

1. Liesker JJW, Wijkstra PJ, Koeeter GH, Postma DS, Kerstjens HAM. A systematic review of the effects of bronchodilators on exercise capacity in patients with COPD. Chest 2002; 121: 597-608.
2. Mahler DA, Donohue JF, Barbee RA, et al. Efficacy of salmeterol xinafoate in the treatment of COPD. Chest 1999; 115: 957-965.

3. Boyd G, Morice AH, Pounsford JC, Siebert M, Peslis N, Crawford C. An evaluation of salmeterol in the treatment of chronic obstructive pulmonary disease (COPD). Eur Respir J 1997; 10: 815-821.

4. Grove A, Lipworth BJ, Reid P, et al. Effects of regular salmeterol on lung function and exercise capacity in patients with chronic obstructive airways disease. Thorax 1996; 51: 689-693.

5. O'Donnell DE, Lam M, Webb KA. Measurement of symptoms, lung hyperinflation, and endurance during exercise in chronic obstructive pulmonary disease. $\mathrm{Am}$ J Respir Crit Care Med 1998; 158: 1557-1565.

6. O'Donnell DE, Lam M, Webb KA. Spirometric correlates of improvement in exercise performance after anticholinergic therapy in chronic obstructive pulmonary disease. Am J Respir Crit Care Med 1999; 160: 542-549.

7. Oga T, Nishimura K, Tsukino M, Hajiro T, Ikeda A, Izumi $\mathrm{T}$. The effects of oxitropium bromide on exercise performance in patients with stable chronic obstructive pulmonary disease. Am J Respir Crit Care Med 2000; 161: 1897-1901.

8. O'Donnell DE, Revill SM, Webb KA. Dynamic hyperinflation and exercise intolerance in chronic obstructive pulmonary disease. Am J Respir Crit Care Med 2001; 164: 770-777.

9. O'Donnell DE, Webb KA. Exertional breathlessness in patients with chronic airflow limitation. The role of lung hyperinflation. Am Rev Resp Dis 1993; 148: 1351-1357.

10. O'Donnell DE, D'Arsigny C, Fitzpatrick M, Webb KA. Exercise hypercapnia in advanced chronic obstructive pulmonary disease: the role of lung hyperinflation. $\mathrm{Am}$ J Respir Crit Care Med 2002; 166: 663-668.

11. Vincken W, Van Noord JA, Greefhorst A-PM, et al. Improved health outcomes in patients with COPD during 1 year's treatment with tiotropium. Eur Respir J 2002; 19: 209216.

12. Casaburi R, Mahler DA, Jones PW, et al. A long-term evaluation of once-daily inhaled tiotropium in chronic obstructive pulmonary disease. Eur Respir J 2002; 19: 217224.

13. Littner MR, Ilowite JS, Tashkin DP, et al. Long-acting bronchodilation with once-daily dosing of tiotropium (Spiriva) in stable chronic obstructive pulmonary disease. Am J Respir Crit Care Med 2000; 161: 1136-1142.

14. Folgering H, Palange R, Anderson S. Clinical exercise testing with reference to lung diseases: indications and protocols. In: Roca J, Whipp BJ, eds. Clinical exercise testing. Eur Respir Mon 1997; 2 (6): 51-72.

15. Mahler DA, Weinberg DH, Wells CK, Feinstein AR. The measurement of dyspnea. Contents, interobserver agreement, and physiologic correlates of two new clinical indexes. Chest 1984; 85: 751-758.

16. Coates AL, Peslin R, Rodenstein D, Stocks J. Measurement of lung volumes by plethysmography. Eur Respir J 1997; 10 : 1415-1427.

17. Cotes JE, Chinn DJ, Quanjer PH, Roca J, Yernault JC. Standardization of the measurement of transfer factor (diffusing capacity). Report Working Party Standardization of Lung Function Tests. European Community for Steel and Coal. Official Statement of the European Respiratory Society. Eur Respir J 1993; 16: 41-52.

18. Quanjer PH, Tammeling GJ, Cotes JE, Pedersen OF, Peslin $\mathrm{R}$, Yernault JC. Lung volumes and forced ventilatory flows. Report Working Party Standardization of Lung Function Tests. European Community for Steel and Coal. Official Statement of the European Respiratory Society. Eur Respir J 1993; 16: 5-40.

19. American Thoracic Society. Standardization of spirometry 1994 update. Am J Respir Crit Care Med 1995; 152: 11071136.

20. Roca J, Whipp BJ, Agusti AGN, et al. Clinical exercise 
testing with reference to lung diseases: indications, standardization and interpretation strategies. ERS Task Force on Standardization of Clinical Exercise Testing. Eur Respir $J$ 1997; 10: 2662-2689.

21. Borg GAV. Psychophysical basis of perceived exertion. Med Sci Sports Exerc 1982; 14: 377-381.

22. Donohue JF, Van Noord JA, Bateman ED, et al. A 6-month, placebo-controlled study comparing lung function and health status changes in COPD patients treated with tiotropium or salmeterol. Chest 2002; 122: 47-55.

23. Pride NB, Macklem PT. Lung mechanics in disease. In: Fishman AP, ed. Handbook of physiology, Section 3, Volume 111, Part 2: The Respiratory System. Bethesda MD, American Physiology Society, 1986; pp. 659-692.

24. Hubmayr RD, Rodarte JR. Cellular effects and physiologic responses: lung mechanics. In: Cherniack NS, ed. Chronic obstructive pulmonary disease. Philadelphia, WB Saunders Company, 1991; pp. 79-90.

25. Van Noord JA, Smeets JJ, Custers F-LJ, Korducki L, Cornelissen PJ. Pharmacodynamic steady state of tiotropium in patients with chronic obstructive pulmonary disease. Eur Respir J 2002; 19: 639-644.

26. O'Donnell DE, Forkert L, Webb KA. Evaluation of bronchodilator responses in patients with "irreversible" emphysema. Eur Respir J 2001; 18: 914-920.

27. Newton MF, O'Donnell DE, Forkert L. Responses of lung volumes to inhaled salbutamol in a large population of patients with severe hyperinflation. Chest 2002; 121: 10421050 .

28. Marrazzini LR, Cavestri D, Gori L, Gatl L, Longhini F. Differences between mouth and esophageal occlusion pressure during $\mathrm{CO}_{2}$ rebreathing in chronic obstructive pulmonary disease. Am J Respir Crit Care Med 1978; 118: 10271033.
29. Shore SA, Huk O, Mannix S, Martin JG. Effect of panting frequency on the plethysmographic determination of thoracic gas volume in chronic obstructive pulmonary disease. Am J Respir Crit Care Med 1983; 128: 54-59.

30. Jones NL. Clinical exercise testing, $3^{\text {rd }}$ Edn. Philadelphia, WB Saunders Company, 1988; pp. 306-307.

31. Diaz O, Villafranca C, Ghezzo H, et al. Role of inspiratory capacity on exercise tolerance in COPD patients with and without tidal expiratory flow limitation at rest. Eur Respir $J$ 2000; 16: 269-275.

32. Witek TJ Jr, Mahler DA. Meaningful effect size and patterns of response of the transition dyspnea index. J Clin Epidemiol 2003; 56: 248-255.

33. Witek TJ Jr, Mahler DA. Minimal important difference of the transition dyspnoea index in a multinational clinical trial. Eur Respir J 2003; 21: 267-272.

34. O'Donnell DE, Voduc N, Fitzpatrick M, Webb KA. Effect of salmeterol on the ventilatory response to exercise in COPD. Eur Respir J 2004 (in press).

35. Belman MJ, Botnick WC, Shin JW. Inhaled bronchodilators reduce dynamic hyperinflation during exercise in patients with COPD. Am J Respir Crit Care Med 1990; 153: 967-975.

36. O'Donnell DE, Bain DJ, Webb KA. Factors contributing to relief of exertional breathlessness during hyperoxia in chronic airflow limitation. Am $J$ Respir Crit Care Med 1997; 155: 530-535.

37. Martinez FJ, Montes de Oca M, Whyte RI, Stetz J, Gay SE, Celli BR. Lung-volume reduction improves dyspnea, dynamic hyperinflation, and respiratory muscle function. Am J Respir Crit Care Med 1997; 155: 1984-1990.

38. O'Donnell DE, McGuire M, Samis L, Webb KA. The impact of exercise reconditioning on breathlessness in severe chronic airflow limitation. Am J Respir Crit Care Med 1995; 152: 2005-2013. 